\title{
The Etiology of Multiple Personality
}

\author{
By Paul Horton and Derek Miller
}

$\mathbf{I}$ HAS BEEN ESTIMATED that fewer than 100 cases of multiple personality have been reported in the last century. There have been less than a dozen reported cases in the last 50 years. Thigpen and Cleckley ${ }^{1}$ writing in 1954, and referring to multiple personality as the psychiatric "unicorn or centaur," pointed out that the most illustrative and meaningful cases occurred more than a half century earlier. Unfortunately, these case reports employed a psychological frame of reference that restricts their usefulness for today's clinician and the etiology of the syndrome remains obscure.

There is even a legitimate question as to whether or not multiple personality is an artifact of investigation. Much of the literature is unclear as to the techniques used by investigators. In the reported cases of Wholey ${ }^{2}$ and Lipton, ${ }^{3}$ for example, these researchers rather than their patients provided names for the alternate selves. Breuer's ${ }^{4}$ Anna O. had a "bad self," a 19th century psychological concept, which does not appear to have been well encapsulated as a personality. Reported cases rely heavily on hypnotic techniques for elucidating the various personalities. Apart from the possibility that the syndrome is an artifact of hypnosis, suggestion, in a patient with a hysterical personality, can reinforce any preexisting multiple personality ideas the patient might have. If a therapist speaks to one or another of the personalities, the idea that these are separate within the self can be supported.

Prince ${ }^{5}$ acknowledged the role of hypnosis in causing the amnesia of one self for the others: "a new synthesis and more complete dissociation of the B complex had taken place through the experience of hypnosis." Similarly William James ${ }^{6}$ observed: "Having discovered this deeper trance and change of personality in Lucie, M. Janet naturally became eager to find it in his other subjects. He found it in Rose, in Marie, and in Leonie; and his brother Dr. Jules Janet, who was an interne at the Salpetriere Hospital, found it in the celebrated subject Wit ... whose trances had been studied for years..."

The present case does not appear to the authors to have been suggested by her primary physician (P.H.). The patient was initially of special interest in that she was diagnosed as suffering from a severely disturbed schizophrenic reaction. Her mother suffered similarly. Brief intensive analytically oriented psychotherapy with concomitant similar treatment of the mother by another therapist was to be attempted. Hospitalization, which in itself can produce iatrogenic symptoms in schizophrenic patients, ${ }^{7}$ was to be used for only a minimal period of time during an acute crisis. Multiple personality was not being sought but in the course of the patient's treatment three fairly clearly defined alternate personalities were described by her. The case appears to demonstrate that the multiple personality syndrome can exist without suggestion from a therapist. The concurrent treatment of the mother made it possible

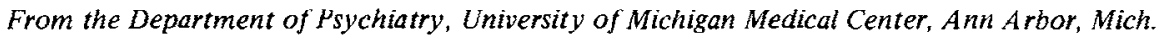

Paul C. Horton, M.D.: Resident of Psychiatry, Department of Psychiatry, University of Michigan Medical Center, Ann Arbor, Mich. Derek H. Miller, M.D.: Chief, Outpatient Psychiatry Department, Professor of Psychiatry, University of Michigan Medical Center, Ann Arbor, Mich. 
to elucidate the significant family dynamics that could explain in part the possible etiology of the syndrome.

\section{CASE REPORT}

The patient was a 16-yr-old lower middle class girl from Detroit who was referred initially to a neurologist with symptoms that included hallucinatory episodes, suicidal ideas and gestures, syncope, and dyspnea on exertion. She complained mainly of "fainting spells," "nerves," and frontal and occipital headaches which lasted from 1 to $3 \mathrm{hr}$. She also described spells of vertigo of approximately $3 \mathrm{~min}$ in duration without reported loss of consciousness. The headaches and vertigo were frequently accompanied by macropsia, micropsia, and double vision. The patient would feel somewhat "groggy" after these episodes. She described her hallucinations as being those of a "monster" with her father's head. Her mother complained that her daughter's behavior could be unpredictably troublesome as when she would steal from her sisters without any apparent awareness of having done so.

Physical and neurological examinations were within normal limits. An electroencephalogram was reported as moderately abnormal; the basic frequency was slow and there werc a number of paroxysmal discharges, abortive spike waves, in the occipital region. This was thought to indicate an organic component to her symptoms, possibly epilepsy. Unfortunately, the patient neglected to return for a repeat electroencephalogram. A moderate hydrocephalus was detected on skull films, the clinical significance of which could not be determined. The working assumption of a psychomotor seizure disorder was made and the patient was given pheonbarbital and dilantin. The neurologist referred her to a psychiatrist for treatment of her emotional difficulties.

The patient was moderately tall, well-developed, fairly attractive, brunette of average intelligence. She was clean and well-groomed. Her speech was animated. She could be articulate and coherent but was frequently discursive and circumstantial. She said, "When I get nervous, I talk a lot." The content of her speech was sometimes superficial, and at other times appeared "silly." Affect was frequently inappropriate. With wide-eyed naive innocence she described being attacked by the monster of her hallucination. She said with a laugh that she had "nothing to live for, couldn't care less" whether she lived or died. She described her hallucination of a "horrible monster with my father's head," and how this hallucination would cause her to panic and to strike out at the monster in self-defense.

The father had deserted the family approximately 4 yr previously, and the patient said that she hated him. In spite of this, she would attempt to call him and see him periodically and, in retrospect, did not know why she would do this. She was aware of his marital infidelities. She described an episode which occurred when she was $10 \mathrm{yr}$ old, 2 yr before he left. She heard her father "sweet talking" his girlfriend on the telephone while her mother was out. She justified her silence about this saying that she was "too scared" of her father to tell her mother. She reported how she had heard him say to his girlfriend, "just a minute while I get rid of the brat," a statement that to her implied murderous intent.

The patient's mother was a 40-yr-old elementary school teacher who was having considerable difficulty in holding her job due to an inability to get to work on time. She appeared as a cold, emotionally distant woman with a tenuous and intellectualized 
relationship with her children. She referred to them by number (one, two, and three), and the patient was "that girl." The mother had accepted psychiatric referral for her daughter because "I just don't understand what gets into her."

Her exhusband had frequently beaten her in front of the children and had carried on numerous extramarital affairs. He was an inconstant provider. When the mother was present he was warm and friendly with his children. He was not rough or abusive and would be highly protective of them when their mother would attempt to discipline them, physically or otherwise. After leaving the family home, he was very conscientious about support money although he showed little interest in seeing his children and would see the patient only when she begged to see him.

The patient is the oldest of four children. She has two sisters, aged 15 and 13, and a brother. The 15 -yr-old sister was described jealously by the patient as an attractive, academically and socially successful girl. She said that she "had heard" from this sister that her father had had sexual "dealings" with her. The 13-yr-old sister was a school and home management problem and a bed-wetter. The 9-yr-old brother was described by the patient as being depressed and wanting to run away from home.

Because of her grossly inappropriate affect, intermittent hallucinations and other wise relatively intact personality, the patient was diagnosed as suffering from a schizophrenic reaction, paranoid type. There is much confusion and debate over the differential diagnosis of schizophrenia and hysterical psychosis. However, the treatment plans for this profoundly psychotic girl were to be the same whether she was perceived as hysterically psychotic or schizophrenically psychotic. The acute symptoms were thought to be related to her unresolved mourning about the loss of her father. He was hated for leaving her but the hallucination represented, in part, her identification with him and stressed her need for him. The mother, brutally treated by her husband, thus an abused and devalued individual, was an unsatisfactory identification model for her daughter. The patient was to be treated with psychotherapy and chemotherapy. Stelazine, $6 \mathrm{mg}$ daily, was prescribed.

Mother and daughter were both to be seen once weekly by separate therapists whose relationships were to be similar to those described by Miller. ${ }^{8}$ The therapeutic focus with the patient was to help her mourn the loss of her father and to reinforce her feminine identification. With the mother the goal was to assist her to provide more structure and controls in the patient's life, and her own, and help her feel more warmly towards her children.

\section{COURSE OF TREATMENT}

The patient was seen for approximately 17 outpatient hr over an 8-mon period. During that time, in a period of crisis, she was hospitalized for 1 wk during which she was seen daily. She missed many outpatient sessions, for reasons in and out of her control. On one occasion she arrived very late and was grateful and relieved that the therapist had waited for her.

From the outset, the most striking feature about the patient was her markedly variable appearance. Initially, she appeared as a profoundly disintegrated personality: tense, anxious, suicidal, and hallucinating. Stelazine and supportive therapy, along with interpretations about the possible meaning of her hallucinations, seemed to lead to a good deal of ego integration. The hallucinations and suicidal ideation were tempo- 
rarily alleviated. She then appeared as a dowdy, vapid, vacuous, intermittently withdrawn, superficial, timid, and compulsive midadolescent. Her clinical picture was punctuated on occasion by extremely loose associations and inappropriate affect.

There was a quality of martyrdom about her. She described her feelings of abuse and persecution at the hands of her sisters; how she was frequently accused of stealing things, starting fights, and of being "crazy." She said, "I just don't know what is happening around that house. I'm always getting accused of things I didn't do." At this time her boyfriend was a typical "all American boy," a " $6 \mathrm{ft} 2$ in football player" who accompanied her "to church every Sunday." Apart from this he seemed to be mainly interested in taking her on "rollerskating" dates. She described him as "pure frat-he wears very nice clothes like you-he's the kind of guy I've been looking for."

After four sessions, the patient wanted to stop therapy because it was "costing too much," the medicine was "helping" and she thought she "could manage." Nevertheless, she accepted the therapist's recommendation that she continue therapy. Then, another side of her personality began to show itself.

A boisterous, loud, vulgar, irritable, and seductive vamp appeared. Wearing heavy make-up and miniskirts, she was blatantly seductive to the therapist, making inquiries about his personal life and conjectures about what "sort of woman" his wife must be. The contrast with the personality of the previous week was striking and the therapist took pause to wonder if he was treating the same girl. The patient's mother complained to her therapist of the patient's sudden uncontrollability which kept her "out at all hours of the night." She hoped that Gloria was telling her doctor everything "he needs to know." Gloria described going to wild parties where she became drunk and was approached by older men. She saw herself as a "swinger." She almost certainly had sexual intercourse with men in their midtwenties. She stopped taking her medication. Nightmares of undetermined content and hallucinations of her father began to torture her again. She began to have fainting spells and seizure-like episodes. She had changed from a seemingly religious, ethically sensitive, and timid individual to a kind of hardened woman of the world.

The patient, in reflecting upon her marked change in behavior, described herself in the following way: "I have split personalities $-I$ don't understand me at all. The real me is a musician who constantly likes to go to church and constantly work. But sometimes the real me is a rough, tough kid who likes riding on motorcycles. I've always wanted one since I was a kid. I just love that image" (enthusiastically). "I love my image of being on a motorcycle or a horse. I feel like an outcast" (plaintively). "I am the unhappiest kid in the world. I could have cried my face out this week, but I took everything as a joke." At that time it did not occur to the therapist that the patient might be suffering from a multiple personality syndrome and he did not seek clarification of the phrase, "split personalities" which the patient had used in reference to herself. His theoretical model was that she could now safely show him a side of her personality which had been present and hidden; his recommendation that she continue therapy had allowed the patient to feel that she would not be rejected if she exposed the therapist to her aggressive "monstrous" sexual self.

She described peculiar experiences in which she fainted for approximately 10 or 15 min. She said that before fainting she felt depressed and upon awakening felt lightheaded and giggly. She also described somnambulism, a frequent occurrence brought to her attention by her mother and siblings. There was some question of theft: "I have 
been very confused this week-everybody has been missing money around the house, including myself. How could I steal from my own purse? When I got up one morning, I found my clothes laid out for me and I didn't do this myself. Mother yelled 'Gloria' at me, and, for some reason, I didn't answer. This is all really very confusing. I daydream constantly. I don't know whether or not I am really crazy, but, if I was to go out in the middle of the night and kill somebody, that would be serious. Mother says that I answered the telephone while sleepwalking the other night. She said it hadn't rung. I think I must have been trying to recall what happened to me a long time ago-I think I must have felt like I was going back to when this all started 4 years ago."

The patient dated the onset of her difficulties very specifically to the time when her father left home. Then, to the therapist's surprise, she began to introduce a different self. "Four years ago I was like I am now, but I did not go by the name of Gloria. I went by the name, Sue. I wished that I would have been named Sue. I love that name, Susan. This all began when my father left. It was like I split up into different parts, and I would try out all these things to find me." She went on to describe four different personalities named Debby, Susan, Carolyn, and Gloria. As Debby, Susan, or Carolyn, the patient was unaware of the other three personalities; as Gloria she was aware of the other three and Gloria was the disintegrated personality who required and sought help.

\section{THE MULTIPLE PERSONALITY SYNDROME}

All of the personalities were named and described by the patient. She was to acknowledge that all of them had made their appearance at one time or another during the course of therapy. When it became clear that the patient was suffering with the multiple personality syndrome, a decision had to be made about how best to effect ego-integration. Because she could be so self-destructive, especially in her relationships with older men, there was an urgency about treatment. It is, of course, tempting for the therapist to become an investigator when he is presented with a rare and interesting syndrome. In this case, however, hypnosis, amytal interviews, history-taking detours, etc., had to be ruled out as was any manner of speaking or interpretation that would reinforce splitting. Partial ego-integration was effected relatively quickly and we did not learn much about her identifications and their relationship to the various personalities as would have been desirable. It was not possible to learn, for example, to what extent she had identified with her siblings, especially her envied 15 -yr-old sister. It was also quite unclear as to whom the identification "Debby" represented.

She described how she had reacted when the therapist would misname the personality present: "When I was 'Susan,' and you would call me 'Gloria,' I would say to myself, 'I am Sue'." This observation was not in response to any inquiry about the differing personalities since they were all spontaneously described. The therapist did not ask the patient about them until they had all been described over several sessions. The therapist was careful to question her about them in a way that would not reinforce the idea of there being, in fact, separate selves. The patient seemed only too ready to reify disparate elements of her personality into mutually exclusive "selves."

The earliest alternate personality seen by the therapist, the responsible church-going girl with a straight boyfriend, appears to have been an individual the patient called "Debby" a "strange person who is difficult to explain, a shy type who doesn't want involvement and who is quite lonely." A second personality appears to have been 
Carolyn: "A girl that constantly wants to be on the go, to drink, smoke, wear high heels, swear, see the world, beat everybody else, outgoing, a go-go girl." (This style of life closely resembled that of her father and his paramour.) Susan was the first personality to emerge after the father's desertion; she was the individual first named separately by the patient to the therapist. She was described by Gloria as "a quiet, pretty type who gets along well with others-it's difficult to describe her, she does every thing on the rebound." The patient said that Susan had appeared when she was 12 , just after her father had left. She stated that, in fact, she had known a girl like Susan whose father was superintendent of schools. "We had exactly the same things about us. We both always tried to be know-it-alls. She was always very popular with the kids and I always hated her." She described this girl and her affectionate relationship with her father with obvious jealousy.

The fourth personality was Gloria, the girl who was in treatment and who knew about the other three. She was the individual who was to later say: "It is so strange when I look back on it now. I figure I am sane now. Should I try to forget it? I don't think they will come back again. I try to catch myself real quickly if I feel them coming back. I'm afraid I don't believe that I could go through it again. I don't think I can stand the nightmares. My friends have noticed a complete change in me lately. They say that it is an absolutely wonderful change. Is this the real me? The other people would only last a few days to a few weeks. If this is the real me, I should be like this constantly."

She said that she had spoken of her different selves because "I can't let the past bother the future. It puts me down. I feel more free now that the issue is closed." The reason she gave for her failure to discuss her multiple personalities early in treatment was her fear that "they would try to come out and fight back-I was afraid that I would fall overboard, that I wouldn't get a voice in. I couldn't let things come out into the open until I felt safe-I felt that these people would come out, that I would look into the mirror-anyone of those girls would be there and I thought to myself, should I tell him now or later? You're the only person I've ever told about these other people."

The patient had earlier experienced dissociative episodes during the therapy sessions. During the twelfth hour the patient had begun to describe her other selves. As the therapist sat listening and not commenting, the patient began to appear dazed: "One day, I looked into the mirror and it wasn't me-my mind is going off now. I am trying to picture what she looked like. She was dressed like ... Susan! Susan ... was the soft-spoken one. This scares me, I was gone! It's ... it's so weird." She appeared frightened and then urgently explained: "Two years ago this happened. I just went berserk. I felt like I was moving. I felt like I was going to fall off and keep falling, falling ..." Suddenly there was an outburst of raucous laughter which startled the therapist. Later in the hour she cried out with utter conviction, "Dr. H., there is somebody else in this room! I think it's Susan!"

Following the patient's description of her multiple selves, she appeared to gain a good deal of ego-integration. She took a new job, enrolled in correspondence courses to complete her high school education, and became much more reflective about herself and her behavior. She and her mother terminated therapy, against medical advice, ostensibly for the same reason. The mother was unable to come to her appointment as her job was again threatened if she left it early once weekly. The patient stopped because she had a new job from which she felt she could not leave. The therapist 
offered to continue to be available to her if she so wished. Since termination of therapy, the patient has called the therapist four times at approximately 2-mo intervals. Each time she has described some troublesome decision she has felt compelled to make and has asked for an apointment. Each time the scheduled appointment has been cancelled by "Gloria."

\section{DISCUSSION}

One explanation of the multiple personality syndrome is that the patient, like Masserman's "Bernice," seems to have identified with an envied rival, in this case a socially successful and very bright daughter of the superintendent of schools. This identification appears to be related to Gloria's attempt to deny her unwanted, unloved self by drastically revising her total personality in the image of a girl who attracted, rather than repelled others; particularly she sought the combination which could attract and hold her father's love. The adoption at a conscious level of part of the perceived personality of another who is thought to be desirable, is in the natural identification process of all individuals. This partial identification is incorporated into a healthy personality and is not seen as alien. However, the attempt of the personality to create total change and incorporate all of another's personality is not a viable possibility. Some identification with parents is made, even in a situation like the patient's; a cold distant intellectualizing mother and a dissociated father. However, these repelling aspects reinforce the need to try to be completely like someone else. The attempt to become a totally new person is reinforced in adolescence if the basic identification with the parent of the same sex is inadequate.

The father's dissociation is to be understood in the following way: he showed two distinct personalities in the household, being brutal and aggressive toward the mother, and often kind and gentle with the children when the mother was present; he was also very sexual, making his affairs known to his daughters. It is possible that Gloria had had some sort of incestuous affair with him; at any rate she yearned for it. She said she often wondered if her father had "done something" to her and bitterly alleged that he had had sexual dealings with her sister. The father was, however, quite proper in his sexual behavior with his daughters when their mother was present. The mother never expressed conscious concern about the occurence of incestuous behavior. After leaving the family, the patient's father lived alone with his half-sister. Gloria's mother said she was ashamed of such "carrying-on." It is significant that the terrifying hallucinations of being attacked by "a monster with my father's head" would occur only when Gloria was alone in her bedroom.

It is probable that any child who is the object of incestuous relationships with one parent perceives the other parent as being collusive in that he or she makes no attempt to stop the affair. Thus, the parent of the same sex is also perceived as being like two people; one of whom disapproves of the child's sexuality, the other of whom encourages, through default, its appearance. Both parents can be perceived by the patient as having multiple personalities in that they behave with gross inconsistency. Lipton's case $^{3}$ also had "terrifying visual hallucinations of her father sexually assaulting her," and it was known that this patient had in fact had incestuous relations with her father and brothers.

The older literature on multiple personality does not adequately explore family interpersonal relationships. A clearly incestuous relationship was reported by Lipton. ${ }^{3}$ 
Most if not all of the cases seem to have become florid, however, after the loss of a significant identification figure whom the patient was trying to make the primary model. Masserman's" "Bernice" split after losing her "loved and successful sister surrogate." Riggall's ${ }^{10}$ patient disintegrated upon his brother's death: "the alter ego of his disassociation." Miss Beauchamp ${ }^{5}$ fragmented after her husband's death and Anna $O$. after her father's death. Eve White ${ }^{1}$ suffered splitting after rejection by her parents and later after loss of her daughter.

In addition, all the cases of multiple personality in the literature including the present case, so far as can be deduced, have the pattern of having a parent of the same sex who fails to be a satisfactory identification figure. The appearance of the multiple personality syndrome follows the loss of an individual who appears to have been a partial substitute for this person. Riggall's ${ }^{11}$ male patient, for example, could not identify with his father. Instead he formed an exceedingly close long-term relationship with his older brother. The death of this brother resulted in the dissociation. The same pattern occured with "Bernice."

The present case and a study of the literature suggests, then, the following dynamics of the multiple personality syndrome: (1) the parent of the same sex is an unsatisfactory identification model and appears to show multiple personality facets that are contradictory; (2) the parent of the opposite sex presents multiple facets of personality functioning that are quite distinct and contradictory within the family structure; (3) the individual has the capacity to make meaningful emotional relationships so that substitute identification figures are sought; the syndrome follows the loss of these relationships; (4) to maintain marginal ego integration, knowledge of the different personalities is repressed. A failure of this dynamic repressive mechanism leads to acute ego disintegration in the absence of therapy. With adequate treatment, however, it becomes possible for the patient to become aware of multiple selves. In the present case, "Gloria" could say "Four years ago I split up." because treatment was being helpful.

The relationship, if any, of the occipital dysrhythmia and moderate hydrocephalus observed in this patient to the onset of the syndrome is unclear. Condon et al. ${ }^{12}$ examined a film of Thigpen and Cleckley's patient and detected a divergent strabismus. They also note that visual disturbances are common complaints of those with the multiple personality syndrome. They hypothesize a "more than purely semantic relationship between the dissociation of a personality and the dissociation of normal occulomotor parrallelism." The present case had a history of transient micropsia, macropsia, and strabismus.

Descriptively speaking, the multiple personality syndrome entails a defect in the retrieval link of memory. The hypothesis that an ocular disorder is related to the special transient memory deficit of multiple personality would require, therefore, a corollary hypothesis linking memory to eye signs. The complete hypothesis would then state that the tensions associated with confused and substitute identification models reinforced by the loss of such a figure lead to an upsurge of affect such that a retrieval memory defect becomes manifest. The psychology and biology of memory, however, have been little studied insofar as they affect psychiatric syndromes and there is, to our knowledge, no known specific relationship between memory defects and eye signs. Further elucidation of the etiology of this disorder may be assisted by the future data and models of the psychology and biology of memory. 


\section{SUMMARY}

A case of multiple personality in a 16-year-old girl demonstrated that the disorder can be noniatrogenic. The patient spontaneously named and described three altemate personalities. A crucial determinant in this and other reported cases is the inability of the patient to adequately identify with the same-sex parent. This leads to unstable extraparental identifications that makes splitting of ego functions likely under stress. The relationship, if any, of ocular defects and or cortical disorders to the onset of this syndrome is unclear but bears furthur exploration.

\section{REFERENCES}

1. Thigpen, C. H., and Cleckley, H.: A case of multiple personality. J. Abnorm. Soc. Psychol. 49:135-151, 1954.

2. Wholey, C. C.: A case of multiple personality. Amer. J. Psychiat. 12:653, 1933.

3. Lipton, S.: Dissociated personality: A case report, Psychiat. Quart. 17:35, 1943.

4. Breuer, I., and Freud, S.: Fraulein Anna O: The Complete Psychological Works of Sigmund Freud, Vol. II, London, Hogarth 1955, p. 21.

5. Prince, M.: My Life as a Dissociated Petsonality: Clinical and Experimental Studies in Personality, Cambridge, Mass., Sci-Art, 1929, p. 267.

6. James, W.: The Consciousness of Self: The Principles of Psychology. New York, Dover, 1950, p. 291.
7. Miller, D., and Clancy, J.: An approach to the social rehabilitation of chronic psychotic patients. Psychiatry 15:435, 1952.

8. - : Family interaction and adolescent therapy. In Lomas, O. (Ed.): The Predicament of the Family, London, Hogarth, 1967, p. 34.

9. Masserman, J. H.: The Dynamics of Adaptation: Principles of Dynamic Psychiatry, Philadelphia, Saunders, 1961, p. 32.

10. Riggall, R. M.: Dual personality. Lancet 1:1155, 1923.

11. - : A case of multiple personality. Lancet 2:846, 1931.

12. Condon, W. S., Ogston, W. D., and Pacoe, L. V.: J. Abnorm. Psychol. 74:618, 1969. 